\title{
A dupla caixa e o espaço em branco no processo de alfabetização
}

\section{The double box and the blank space in the literacy process}

\author{
Márcia Martins de Oliveira ABREU ${ }^{1}$ \\ Adriana Pastorello Buim ARENA ${ }^{2}$
}

\begin{abstract}
Resumo
Este artigo é parte de uma pesquisa de doutorado, cujo propósito era o de desenvolver uma possibilidade metodológica de trabalho com crianças em processo de apropriação da língua escrita tendo como suporte textos construídos e utilizados socialmente. Para o alcance do objetivo foi realizada uma pesquisa de intervenção com uma turma de $1^{\circ}$ ano do Ensino Fundamental de uma escola da rede federal de ensino localizada na cidade de Uberlândia/MG. Entre os diversos temas discutidos na tese, elegeu-se para esta publicação o debate em torno do uso da letra maiúscula durante o processo de alfabetização. Entre alfabetizadores ainda existe a crença de que as letras em caixa alta são mais simples para serem aprendidas e, por este motivo, é oferecido às crianças pequenas este tipo de letra. Entretanto, os resultados indicaram que o envolvimento dos sujeitos no trabalho com a dupla caixa auxiliou qualitativamente o processo de alfabetizaçáo.
\end{abstract}

Palavras-chave: Alfabetização. Apropriação da cultura escrita. Dupla caixa. Espaço em branco.

\begin{abstract}
This article is part of a doctoral research whose purpose was to develop a methodological possibility of working with children in the process of appropriation of written language supported by texts constructed and used socially. In order to reach the objective, an intervention research was carried out with a 1st grade class from Elementary School of a school of the federal education network located in the city of Uberlândia / MG. Among the various topics discussed in the thesis, the debate about the use of the capital letter during the literacy process was chosen for this publication. Among literacy teachers there is still the belief that capitals letters are simpler to learn and, therefore, to small children are offered this type of writing. However, the results indicated that the subjects 'involvement in the work with the double box qualitatively assisted the students' literacy process.
\end{abstract}

Keywords: Literacy. Appropriation of written culture. Double carton. Blank space.

1 Doutora em educação. Professora da escola de aplicação - ESEBA - da Universidade Federal de Uberlândia, MG. E-mail: mmartinsabreu@uol.com.br

2 Doutora em Educação. Professora da Faculdade de Educação da Universidade Federal de Uberlândia, MG. E-mail: dricapastorello@gmail.com

\begin{tabular}{|l|l|l|l|l|l|} 
R. Educ. Públ. & Cuiabá & v. 28 & n. 68 & p. $465-484$ & maio/ago. 2019 \\
\hline
\end{tabular}




\section{Introdução}

A proposta metodológica defendida na tese, na qual se baseia este artigo, se realizou a partir de Planos de ação constituídos por sequências didáticas específicas idealizadas para diferentes gêneros textuais. A organização de todo o trabalho foi norteada por quatro eixos temáticos: Contexto extratextual, Texto gráfico, Palavra e Leitura. Devido ao curto espaço concedido a esta publicação será discutido apenas o uso da letra em caixa dupla no processo de alfabetização em atividades geradas no interior do eixo denominado texto gráfico, cuja função era mostrar às crianças a materialidade de um gênero expresso em um texto gráfico. Os dados foram gerados na relação entre as crianças e a pesquisadora durante o ano letivo de 2016. Os instrumentos metodológicos para gerá-los foram os próprios Planos de ação juntamente com a observação participante, a construção de diário de campo e a transcrição das filmagens de micro entrevistas orais e escritas, realizadas em micro eventos do cotidiano, com os sujeitos sobre as suas produçóes, no decorrer das experiências planejadas e vivenciadas. A pesquisa teve como base os pressupostos teóricos defendidos por Volochinov (2017) sobre linguagem, e pela Teoria Histórico Cultural representada especialmente por Vigotski (2001). Foram pressupostos fundamentais para nortear o trabalho e as análises dos dados. Para a idealizaçáo da proposta pedagógica de intervenção foram fontes de inspiração Bajard (2012), Jolibert (1994), Marcuschi (2007) e Bernardin (2003). A análise de dados se apoiou ainda em estudos de autores de várias áreas, dos quais podem-se destacar, além dos já mencionados, Arena (2010), Fiorin (20012) e Smolka (2012).

O texto trabalhado com as crianças e selecionado para este artigo se refere ao gênero literário. A escolha da literatura infantil para iniciar o trabalho se concretizou pelo reconhecimento da sua importância na formação do homem e de suas funçóes psíquicas já muito estudadas. (ARENA, 2010; BAJARD, 1999; JOLIBERT, 1994; VIGOTSKI, 2009). Em virtude desse entendimento, selecionou-se o texto poético Leiláo de Jardim de Cecília Meireles, retirado do livro Antologia de Poesia Brasileira para crianças. Esse plano de ação sequencial foi iniciado no dia 22 de março de 2016 e finalizado no dia 13 de abril de 2016.

\section{Texto gráfico - a dupla caixa e o espaço em branco}

Primeiramente, o texto Leilão de Jardim foi apresentado à turma de maneira ampliada. Essa forma de apresentação do texto impresso foi feita de maneira que o formato textual fosse conservado, mas em tamanho muito maior que o apresentado em seu suporte original. Pela apresentação do poema ampliado em 
porta-texto, foi chamada a atenção dos alunos para os contornos que o constituem, bem como para suas características.

O trabalho na alfabetização inicial introduzido por meio do texto, em sua totalidade, com toda a sua estrutura gráfica e a semântica, carregada de sentido, resulta na conquista de um processo significativo para os sujeitos. De acordo com Jolibert e Jacob (2006, p. 187 - 188),

De fato, aceitamos realmente que as crianças podem construir as suas competências em leitura, e que podem fazê-lo de maneira sólida e duradoura, temos de aceitar, sem dramas, uma intervenção na ordem cronológica das conquistas de estruturas por parte das crianças. Todos os dias podemos observar que é mais fácil e mais significativo, para elas, identificar um tipo de texto ou formular hipóteses a partir de um título do que abstrair letras, já que as letras são o "cúmulo" da abstração e da arbitrariedade. [...] o que buscamos prioritariamente na leitura é o significado de um texto. As letras identificadas constituem um dos meios, entre outros, que fornecem chaves para elaborar esse significado. (Grifos das autoras).

Nessa perspectiva, considera-se que por meio do texto, revisitado pelos alunos em diferentes momentos, é possível não apenas proporcionar às crianças a possibilidade de aprender o sistema de escrita, mas, concomitantemente no movimento dessa aprendizagem, se apropriar dos sentidos. No caso do texto poético, foi possível às crianças entenderem que é uma produção cujo objetivo é impressionar o leitor, causando sensaçóes, podendo variar a quantidade de versos e estrofes, usar rimas ou não. Neste sentido, o texto possibilitou questionamentos que se direcionaram tanto para o seu conteúdo como também para a sua forma por meio da exploraçáo de seus elementos, tais como nome/título, quantidade de versos, formato de estrofes, rimas, dentre outros.

O trabalho realizado a partir dos textos apresenta possibilidades infinitas por apresentarem por meio de suas estruturas gráficas variadas a manifestação de diferentes discursos. Diante essa riqueza de formas contidas nos textos, cada um, orientado pelos seus singulares contextos, seus sentidos expressos em seus enunciados, amplia o entendimento do que seja a escrita. De acordo com Fiorin (2006, p.69),

O gênero somente ganha sentido quando se percebe a correlação entre formas e atividades. Assim, ele não é um conjunto de propriedades formais isolado de uma esfera de açấo, que se realiza em determinadas coordenadas 
espaço-temporais, na qual os parceiros da comunicação mantém certo tipo de relação. Os gêneros são meios de apreender a realidade.

Os gêneros são considerados importantes pelos sentidos que a ele podem atribuir os sujeitos. A valorizaçáo do sentido náo descarta a constituição de sua forma, ao contrário, ela passa a ser identificada pelo sentido que porta porque "a forma é orientada pelo contexto e se constitui em um signo, embora estejam presentes sua natureza de sinal e o momento do seu reconhecimento" (VOLOCHÍNOV, 2017, p. 179, grifos meus).

Foi com o entendimento de que "[...] ler é tomar conhecimento de um texto gráfico." (BAJARD, 2007, p. 24) e considerando as variedades da forma (como estruturas) e do contexto (como sentido) que foram planejadas açóes específicas direcionadas, também, às estruturas gráficas dos gêneros. Os sujeitos aprendem por modelos, "através dos outros constituímo-nos. Em forma puramente lógica a essência do processo do desenvolvimento cultural consiste exatamente nisso." (VIGOTSKI, 2001, p. 24). A afirmação de Vigotski destaca a importância do outro na construção do nosso processo de humanização. $\mathrm{O}$ estudo evidenciou claramente que "a base da objetivação não está no objeto em si [...] mas nas relaçóes com as outras pessoas nesta atividade comum e conjunta" (GERALDI, p. 61, 2006), ou seja, nas experiências, nas interaçóes entre os sujeitos.

A objetivação só se concretiza por meio de processos de construção das características humanas na interação, nos processos mediados pelo outro por meio dos objetos, dos instrumentos culturais e sociais. Esse processo de apropriação é o que permite posteriormente a objetivação e recriação dessa humanização. Dessa forma, as características humanas estão muito além do aparato biológico, porque se constroem subjetivamente nos diversos processos de apropriaçáo e de objetivação. Nesse sentido, Barroco e Superti (2014, p. 25) afirmam,

É por meio da atividade que os homens se apropriam das funçôes já constituídas pela humanidade e as tornam suas. Destacamos, com isso, que se o plano biológico se apresenta como condição inicial para o indivíduo nascer no mundo; é somente pelo plano cultural que ele adquire as aptidóes para viver nesse mundo plenamente como humanizado e que forma os órgãos sociais de sentido. Por exemplo: não basta que tenha acuidade visual, é preciso aprender a "ler" o mundo. Nesse sentido, a arte literária, por exemplo, não somente estimula o decifrar dos signos, mas veicula significados, oferece ao leitor elementos para que faça novas composições, novas objetivações. 
Como todos os textos selecionados e utilizados no trabalho foram apresentados em seus suportes originais e em caixa dupla, maiúsculas e minúsculas, na ampliação do texto a ser trabalhado, mesmo quando redigitado, foi mantida a mesma formatação. Essa escolha teve um objetivo metodológico.

Muitos professores alfabetizadores consideram que o uso apenas da letra maiúscula (caixa alta) facilita o processo de apropriação tanto da escrita como da leitura. No entanto, esse entendimento se apresenta equivocado, uma vez que a letra maiúscula não evidencia as importantes particularidades da escrita, especialmente no que se refere à memorização gráfica das letras em seus contextos escritos. De acordo com Bajard (2012, p. 84),

[...] o uso de duas caixas desde o primeiro encontro da criança com o material escrito pode facilitar a memorizaçáo do nome gráfico. De fato a silhueta da palavra, como a vela para o navio, como dizia Alain (Émile-Auguste Chartier, 1978), filósofo francês, é determinante para seu reconhecimento. Portanto o formato Margarida possui mais traços visuais distintos que o formato MARGARIDA. As letras deste último possuem o mesmo tamanho, enquanto as minúsculas distinguem-se por três classes de caracteres - com haste ascendente ou descendente e sem haste.

Foi em concordância com esse entendimento que se fez a opção pela apresentação da escrita em caixa dupla no desenvolvimento de todo o trabalho. A presença da letra maiúscula nos textos não apenas possibilita o reconhecimento das palavras, mas também promove a apropriação das funçóes de cada uma delas. A apresentação das duas letras juntas, maiúscula e minúscula, no trabalho da alfabetização é fundamental, pois além da letra maiúscula demarcar os substantivos próprios, destaca também o início e a finalização dos períodos.

Ao fazer esse destaque no início, a presença da letra maiúscula contribui também para a apropriação da convenção sobre a direcionalidade da escrita, conforme revelou o registro do diálogo de duas crianças no momento de digitação de um refrão do poema:

A. L.: Você fez errado, a (letra) e ficou pequeno! (Fala se referindo ao refrão: E a cigarra e a sua canção?)

A. M.: Mas ele é pequeno mesmo!

A. L: Não! Não é não! O primeiro $\boldsymbol{E}$ é o do começo olha só. (Aponta a letra $\boldsymbol{E}$ inicial do refrão no cartaz). Sempre que tá 
no começo tem que ser grande, só o outro que é pequeno, mas é porque ele tá no meio. (Aponta a letra e dentro do refráo). A. M.: Hum! Mas como é que faz para ficar grande mesmo? A. L.: Aqui ó! (Aponta para a tecla Shift). A mesma que você apertou para fazer esse sinal (Aponta a tecla da interrogação). Aperta as duas junto, ela e a da letra $\boldsymbol{E}$ que ai ele fica grande igual o do cartaz!

(Nota de campo: 30/03/2016).

Conforme revela a nota de campo acima, a letra maiúscula assume a importante função de sinalizar para o leitor também a direção da escrita, contribuindo para a apropriação desta convenção da língua escrita. "A experiência mostra que a presença da letra maiúscula distinta das demais favorece a descoberta do sentido da escrita, já que a primeira fica sempre à esquerda”. (BAJARD, 2012, p. 84-85). Entende-se que o uso da escrita apenas em caixa alta prejudica o processo de desenvolvimento da leitura uma vez que elimina as distinçóes dos formatos das letras e dificulta o reconhecimento das palavras. Sendo assim, considera-se que o uso da caixa dupla na alfabetização especialmente para o aspecto da apropriação da leitura seja fundamental.

Bajard (2012, p. 83) alerta ainda sobre esse aspecto:

Gostaríamos de destacar que a letra maiúscula assume uma funçáo fundamental na leitura. Não somente manifesta no corpo do texto a presença do personagem, como também sinaliza para os olhos o início da frase e, consequentemente, o seu fim. Por meio da letra maiúscula, o leitor vale-se de seu conhecimento implícito da gramática que opera na frase e percebe a função das palavras reconhecidas.

De acordo com o autor, outra importante razão para o uso da escrita em caixa dupla no início da alfabetização seria a valorização por meio da escrita do nome próprio. $\mathrm{O}$ nome de cada criança no processo de sua alfabetização se configura como algo singular e também especial. Por isso, é necessário que se respeite e se valorize essa representação gráfica também marcada pela letra maiúscula em sua forma escrita. Diferentemente da língua oral, a pronúncia de um nome próprio não apresenta essa marcação no primeiro som, ou seja, ela é peculiar apenas à língua escrita. Portanto, apenas com a utilização da escrita em caixa dupla seria possível respeitar o nome das crianças e sua configuração específica. Sobre este aspecto Bajard (2012, p. 54) afirma: 
A palavra rosa não é meu nome, porque o meu nome Rosa possui uma letra grande". Esse respeito ao nome próprio da criança é a principal razão que leva a escolher uma grafia com caixa dupla: letras maiúsculas e minúsculas. De fato, a presença da maiúscula no nome próprio é uma marca da escrita sem correspondência na língua oral. $\mathrm{O}$ uso exclusivo da maiúscula, como é praticado tradicionalmente, anula essa característica. Por que escolher uma tipografia - a maiúscula (caixa alta) - na qual não se manifesta essa especificidade da escrita? Vale a pena mostrar à criança que seu nome possui um mérito que as outras palavras da língua não possuem. (Grifo do autor).

O trabalho se desenvolveu levando em consideração todas essas vantagens da escrita em caixa dupla para o desenvolvimento da leitura por meio do acesso aos textos no mesmo formato em que eles apareceram nos demais contextos sociais. $\mathrm{O}$ texto ampliado foi retomado em diferentes momentos, por esse motivo, sempre que apresentado eles ficavam afixados nas paredes da sala em todo o decorrer da efetivaçáo do Plano de Ação e também no período de efetivação do próximo Plano de ação.

Em alfabetizaçáo, as paredes da sala podem funcionar como o principal suporte de diferentes tipos de textos, importantes aliados do alfabetizador. Jolibert e Jacob (2006, p. 260), ao discorrer sobre criação de condiçóes facilitadoras para a aprendizagem, apontam algumas formas de utilizaçáo das paredes:

Propusemos uma sala de aula em que as paredes:

Constituem-se em um lugar para valorizar a produção das crianças.

São ferramentas de trabalho a serviço, prioritariamente, das crianças.

São espaços funcionais a serviço da expressão e das aprendizagens.

Estáo sempre em curso de evoluçáa, transformação e renovação.

Podem ser utilizadas por iniciativa tanto das crianças quanto da professora.

Nas paredes vão:

Os textos funcionais da vida escolar cotidiana.

As informaçôes que chegam regularmente à sala de aula e que devem ser disponibilizadas a todos.

Os textos produzidos pelos próprios alunos, para valorizálos, sem o objetivo de enaltecer os "melhores".

A parede de metacognição ou de sistematizaçóes. 
O texto Leiláo de Jardim afixado na parede da sala em muitos momentos foi retomado para a realização de açóes previstas. Uma das atividades foi a de retornar o texto para a marcaçáo dos espaços em branco entre as palavras, realizada coletivamente. Essa atividade chamou a atençáo pelo fato de os alunos evidenciarem atitudes influenciadas por duas experiências realizadas anteriormente que envolveram recursos relacionados ao computador, a saber: a atividade de digitaçáo de um dos versos do poema no teclado do computador conectado ao Datashow, realizada em dupla e, em outro momento, a atividade individual de localizar, na imagem impressa do teclado do computador, as teclas referentes às letras e aos sinais gráficos correspondentes aos comandos da professora/pesquisadora, traçar e colorir as que faltavam, conforme demonstra a reprodução da atividade abaixo.

Imagem 1: Atividade de localização e marcação das teclas

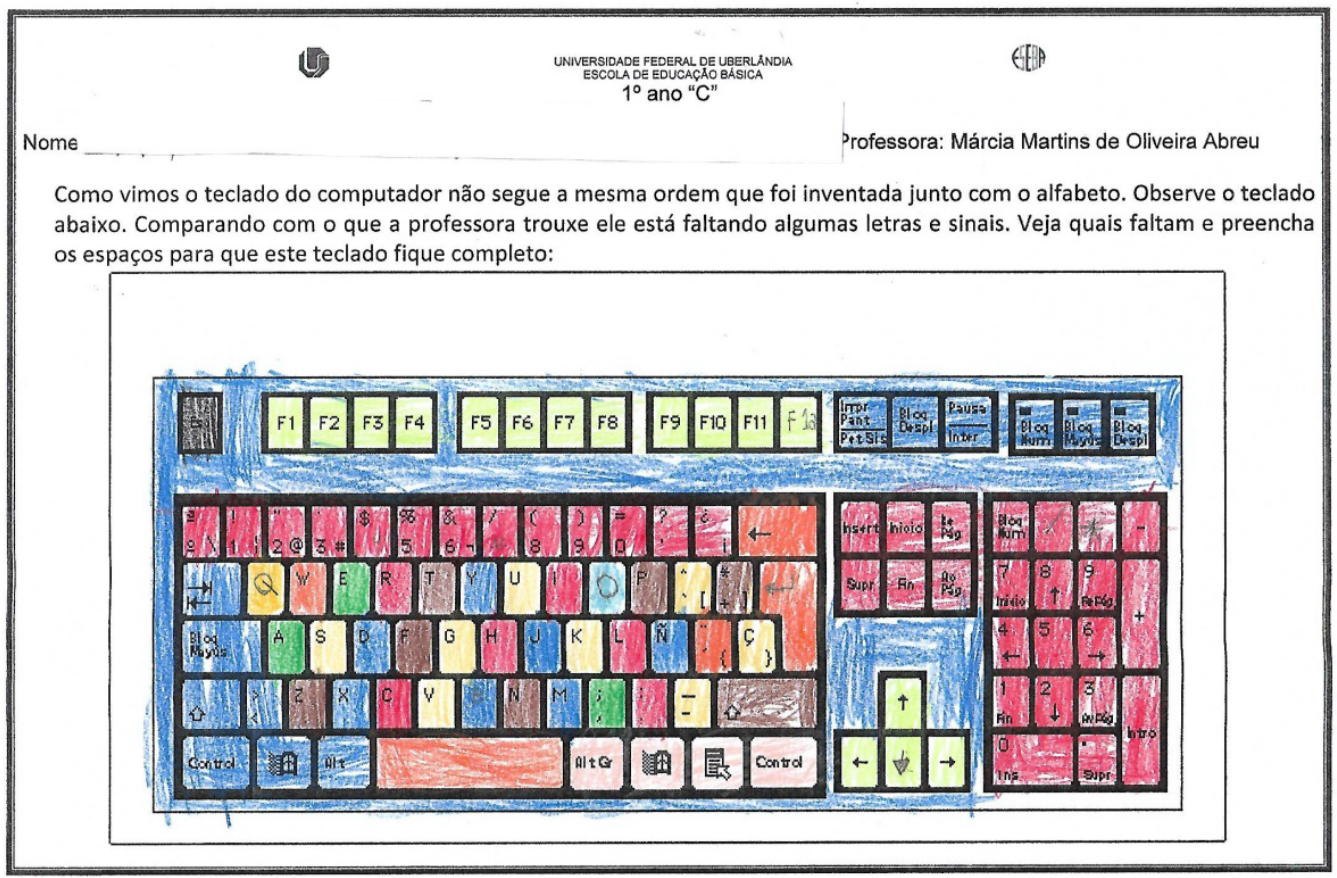

Fonte: Arquivo pessoal da pesquisadora. 
Ao serem solicitados a marcar os espaços em branco entre as palavras, os alunos, em suas mesas, como em um movimento coletivo e sincronizado, começaram a fingir estarem digitando na folha com a imagem do teclado. Como numa brincadeira coletiva, digitavam com os dedos sobre os desenhos das teclas.

Já na atividade de digitação, em dupla, escolhiam e digitavam um dos versos do poema, utilizando o recurso da observaçáo do texto impresso ampliado e o computador conectado ao Datashow. Primeiramente, um escolhia e digitava sozinho o verso escolhido, ou seja, pensava no verso e o digitava escolhendo as teclas que considerava necessárias. Após essa digitação autônoma, era realizada a conferência e a redigitação sob o auxílio do outro aluno e, posteriormente, eles trocavam de posição de forma que ambos vivenciassem as experiências de digitar sozinho, redigitar com o auxílio e também de auxiliar a digitação do outro. Nessa atividade, o uso e a funçáo da barra de espaço do teclado do computador foram o foco mais acentuado, dada a sua importância para a formação do conceito de palavra.

Nessa atividade, os alunos suprimiam palavras e sinais e na maioria das vezes também não digitavam o espaço, demonstrando que ainda não haviam abstraído esse conceito, o que é natural para esta faixa etária. Em posição de auxiliares, bem como a professora-pesquisadora, após a tentativa autônoma de digitação do verso, chamavam a atenção de todos para a consulta ao texto ampliado, para conferir tanto a existência dos espaços em branco entre as palavras como a presença de letras e outros sinais nos versos do poema, redigitando conforme as amostras revelam:

Quadro 1 - Registro das digitações dos alunos realizadas de forma autônoma e com auxílio

\begin{tabular}{|c|c|}
\hline Versos digitados antes da intervenção: & Versos redigitados após a intervenção: \\
\hline loilinu deuxao & E o grilinho dentro do chão? \\
Boleadmutacoe, & Borboletas de muitas cores, \\
ovovedi iazunonio & ovos verdes e azuis nos ninhos? \\
setesapo queejardneo & E este sapo, que é jardineiro? \\
\hline
\end{tabular}

Fonte: Arquivo pessoal da pesquisadora.

Nessa experiência, foi possível identificar que muitos alunos, mesmo não conseguindo abstrair e utilizar o espaço em branco no momento da escrita, e suprimindo várias letras, conseguiam indicar ao colega, quando estavam como auxiliar, o lugar dos espaços entre as palavras bem como as letras e os sinais no texto por meio da visualização desses elementos no texto ampliado em cartaz. Esse fato 
alertou para a importância do outro não experiente junto ao aluno no processo, pois "[...] a posição de um "outro" como interlocutor da criança constitui um elementochave no processo de elaboração e organização do conhecimento." (SMOLKA, 2012, p. 101). Sobre o processo de escrever junto com outro também inexperiente, independente de ser por meio do traçado no papel ou digitado no computador ou em outro recurso digital, Smolka (2012, p. 151) ainda alerta:

No começo do ano, as crianças raramente conseguem ler seus próprios textos, mas elas dizem (sobre) o que escreveram. Um "outro" tenta ler. É justamente da leitura do outro, da leitura que o outro faz (ou não consegue fazer) do meu texto (não esquecer que o "outro" que eu sou como leitor do meu próprio texto), do distanciamento que eu tomo da minha escrita, que eu organizo e apuro esta possibilidade de linguagem, esta forma de dizer pela escritura.

A criança ajudou seu par a propiciar o seu distanciamento da própria escrita e percebê-la com maior nitidez para, a partir das observaçóes do colega, conseguir pensar sobre o próprio texto e reorganizá-lo. Somente após estas duas experiências com o teclado do computador e a discussáo sobre a importância dos espaços em branco entre as palavras é que os alunos foram solicitados a realizar as marcaçóes no cartaz do poema ampliado.

\section{Imagem 2 - Marcação dos espaços em branco entre as palavras}
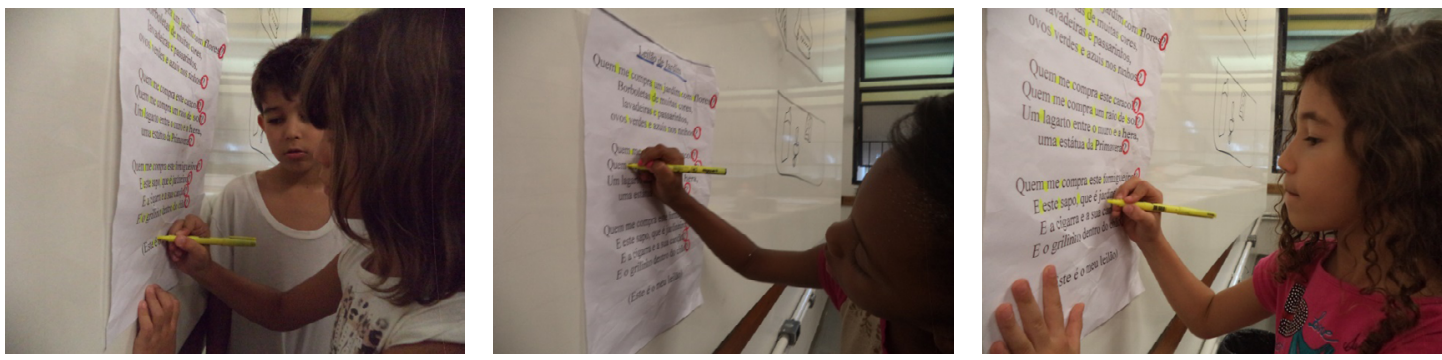

Fonte: Arquivo pessoal da pesquisadora.

$\mathrm{Na}$ referida atividade, enquanto o aluno chamado para marcar o espaço ia à frente, os demais diziam: Vai lá dar o espaço!, ou ainda, É a sua vez de dar o enter! (nas ocasióes em que as frases se finalizavam). Essas expressóes evidenciaram que os alunos, talvez pela experiência anterior de digitação, já atribuíam maior atenção para os espaços em branco grafados na língua 
escrita e uma maior abstração da função tanto da tecla de espaço, utilizada para separar as palavras na digitação, como da tecla enter, utilizada para abrir novo parágrafo.

A utilização de expressões referentes às teclas que desempenham a função de espaçamento e de abertura de parágrafo no ato de digitar, no momento em que demarcavam esses espaços na escrita impressa, demonstrou que conseguiram, em termos vigotskianos, transitar de uma estrutura de generalização à outra, entendendo especialmente, o conceito do espaço em branco entre as palavras, tão importante nesta fase de apropriação da língua escrita. De acordo com Vigotski (2009, p. 246),

Em qualquer idade, um conceito expresso por uma palavra representa uma generalizaçáo. Mas os significados das palavras evoluem. Quando uma palavra nova, ligada a um determinado significado, é apreendida pela criança, o seu desenvolvimento está apenas começando; no início ela é uma generalizaçáo do tipo mais elementar que, à medida que a criança se desenvolve, é substituída por generalizaçóes de um tipo cada vez mais elevado, culminando o processo na formação dos verdadeiros conceitos.

O entendimento sobre a existência do espaço em branco entre as palavras, apesar de ainda pouco valorizado no trabalho dos alfabetizadores, é fundamental para a construção do conceito de palavra. Somente quando a criança possui a real consciência dos espaços em branco na escrita, ela é capaz de identificar as palavras. Sendo assim, até que este conceito não esteja solidamente construído, mesmo quando a criança se utiliza da segmentação na representação por meio da escrita, o uso dos espaços é feito om critérios próprios, conforme a digitação do verso do poema realizada pela aluna E revelou:

uagaoeteou uiae ra

(verso escolhido pela aluna: Um lagarto entre o muro e a hera)

O uso das letras pela aluna demonstra que ela segmentou a escrita em lugares que não havia o espaço em branco e em contrapartida deixou de segmentar nos locais em que eles eram necessários para a formação da palavra. Isso demonstra o quâo o trabalho com o espaço em branco pode contribuir para o avanço dos alunos na apropriação do conceito de palavra. Segundo Bajard (2007, p. 30) 
[...] a língua escrita não é mera duplicação da língua oral: o texto sonoro não se reduz à concatenação dos fonemas, tampouco texto gráfico não se reduz à concatenação das letras. A língua escrita possui, além dos grafemas, um código ideográfico, dentro do qual o espacejamento é o elemento mais relevante.

Nesse sentido, entende-se que, além das diferentes atividades que foram planejadas e realizadas no contexto de cada trabalho com vistas à identificação dos espaços existentes entre as palavras, o uso do teclado do computador auxilia o aluno na apropriação da língua escrita. Ao utilizarem também o teclado, a sua visão se amplia sobre as possibilidades de uso dos caracteres para grafar a escrita. Com o teclado do computador a sua frente, elas possuem a sua disposiçáo não apenas as letras, mas o espaço, os acentos, a maiúscula/minúscula, logo encontram diversas teclas com funçóes que ajudam o desenvolvimento do processo de apropriação da escrita. O termo caractere é utilizado por Élie Bajard $(2006,2009,2012)$ para se referir a cada sinal gráfico da língua escrita. $\mathrm{O}$ autor utiliza-se deste termo fazendo um contraponto com o termo grafema, uma vez que este último é utilizado pela linguística de forma relacionada ao fonema, desconsiderando a escrita como sistema gráfico e limitando-se aos aspectos orais. O caractere, ao contrário, não tem como ser caracterizado pelo fonema uma vez que todos os grafes têm valor relacionado ao significado, ou seja, são ideográficos.

Os diversos caracteres disponíveis nas teclas possibilitam à criança pensar na escrita em sua forma autêntica de funcionamento, ou seja, com todas as possibilidades gráficas de forma independente da pronunciação, sem a valorização da relaçáo letra e som que, quando acentuada nessa fase, apenas prejudica o processo. Bajard (2006, p. 499) ainda elucida que

Escrever uma palavra com o computador supóe manipular essas unidades gráficas. A relaçáo da letra com o fonema passa assim para um segundo plano. Numa época em que as crianças usam o teclado antes do lápis e os adolescentes manipulam com habilidade o celular, no qual a mesma tecla comanda três ou quatro letras, é necessário estar atento ao funcionamento do sistema gráfico sem ficar preso exclusivamente a sua dimensão alfabética. Nessa perspectiva, todos os grafes (letra, minúscula, acento, pontuação, espacejamento) se tornam unidades de uma segunda articulação no nível visual. 
Conforme destaca o autor, a escrita como sistema gráfico, oferecida visualmente na utilização do computador, se configura de maneira prioritária em detrimento da relaçáo com a sonoridade. Nessa perspectiva, reconhece-se o potencial do computador como mais uma importante ferramenta a ser utilizada na alfabetização em meio a tantas outras já conhecidas e utilizadas pela escola. $\mathrm{O}$ uso dessa ferramenta coloca em destaque indícios sobre aspectos tanto físicos como cognitivos em relação aos atos culturais de ler e de escrever nesse suporte. Arena (2011, p. 38), ao analisar essa modalidade de escrita afirma que

Mais do que usar os dedos para escrever, em vez de três abraçadas ao lápis, as crianças podem perguntar sobre todos nos sinais do teclado e sobre todos os sinais na configuração da tela à espera da decisão de um clique do mouse. Mais que clicar, as crianças podem aprender a escrever para o outro, ver e ler para decidir, podem aprender, apesar dos controles didáticos, a transformar conduta herdadas e, sobretudo, abusar da modalidade escrita da linguagem.

Além de possibilitar uma diferente relação com os caracteres, o uso do computador possibilita para sujeitos, professores e alunos, novas concepçóes sobre a linguagem escrita. Por isso, o seu uso conciliado com as demais ferramentas só tem a contribuir com o processo de apropriação da língua escrita. Durante a pesquisa, ficou evidente a necessidade de utilização dos recursos disponíveis na sociedade em diálogo permanente com o processo de alfabetização, como é o caso do computador que tem modificado o processo de desenvolvimento das novas geraçóes.

Ao considerar a escrita como um sistema direcionado à visão humana, o desenvolvimento das açóes com relação à escrita, bem como os recursos utilizados nesse estudo, independente de quais foram, tiveram todos como objetivo a valorização da configuração gráfica dos textos e de seus contextos. Permeados por todos os seus caracteres e não apenas letras, os textos foram, além de trabalhados, também expostos, com as marcas das crianças, para ficarem disponíveis para a visualização cotidiana. Bajard (2006, p. 499) destaca que na escrita existe

[...] antes de mais nada, um valor icônico. Isso quer dizer que qualquer grafe compóe uma imagem com seus vizinhos. Essa função ideográfica, universal, aproxima a escrita portuguesa não só das outras escritas alfabéticas, mas também das escritas consonânticas ou mesmo ideográficas (Sampsom, 1996). O conjunto dos grafes compóe o sistema gráfico que opera semioticamente por 
meio de uma dimensão ideográfica. Nessa abordagem, o sistema alfabético com suas relaçóes fonográficas se torna um subconjunto do sistema gráfico. Todos o grafes possuem valor ideográfico, enquanto apenas uma parte deles possui valor sonoro.

Com a afirmação do autor, fica explícita a importância do valor icônico da escrita, constituída desde a antiguidade e historicamente definida por seus caracteres gráficos, que além de não possuírem a relação direta com a língua oral ainda provocam mudanças significativas no sentido da escrita por meio de suas diversas formas de utilização. "O código fonográfico é um subconjunto do código ortográfico.” (BAJARD, 2009, 192), portanto o trabalho na alfabetização com os caracteres não tem e jamais terá a correspondência fonográfica de forma integral.

A questão de algumas letras apresentarem relação com alguns sons se caracteriza como uma realidade, porém existem razóes específicas para que nessa etapa do desenvolvimento infantil essa relaçáo não seja privilegiada. Uma delas, segundo Bajard (2012, p. 86) é o fato de que a

[...] descoberta do sistema visual, por si só, permite o acesso a toda língua escrita, como mostra o uso da escrita do surdo. Para ele é a substituição da letra /e/ pela /o/ que transforma mãe em mão, e não a substituição de /ãe/ por /ão/ como na linguística clássica. De fato, podemos afirmar que todos os caracteres possuem um valor visual, enquanto apenas uma parte desse conjunto apresenta um valor sonoro. [...]

A outra razão da não pertinência de se relacionar letra e som no trabalho da alfabetizaçáo inicial apontada ainda pelo autor é o fato de que

[...] abordar as relaçôes fonográficas entre letras e sons supóe distinguir o sistema gráfico do sistema fonológico, além de suas relaçóes, trabalho nada simples. É possível realizar um trabalho poético fecundo sobre a música da língua paralelamente à abordagem visual da escrita sem tentar sistematizar as correspondências entre os dois sistemas. Não queremos deixar as crianças dentro de um labirinto - sistema gráfico, sistema fonológico e suas relaçóes - que muito poucos mestres ou estudantes de universidade dominam. (BAJARD, 2005, p.31). 
Acredita-se que apenas um trabalho desenvolvido com a iconicidade da escrita em enunciados completos poderá dar às crianças o acesso não apenas ao sistema escrito em sua totalidade, mas, concomitantemente, a compreensão do real motivo da existência da língua escrita, de sua verdadeira função. O texto possibilita a manifestação do discurso produzido, pois "[...] o texto é o tipo de unidade mais característica tanto da produção quanto da 'recepção' do discurso. É nele que se materializa." (POSSENTI, 2012, p. 251).

Pode-se afirmar que, por meio da materialização do conteúdo de determinado discurso, o texto apresenta a possibilidade de expressão do pensamento humano e, ao mesmo tempo, de interpretação de quem o lê. Ao distinguir texto de discurso Fiorin (2012, p. 162) explica:

A distinçáo entre texto e discurso é necessária porque os procedimentos de discursivizaçáo sáo diversos dos de textualizaçấo, porque eles são objetos que têm modos de existência semiótica diversa: um é do domínio da atualização, o outro, do da realização. Um é da ordem da imanência, o outro, da manifestação: o texto é a manifestação do discurso por meio de um plano da expressáo, o que significa que um mesmo discurso pode ser manifestado por textos diversos. Por outro lado, certas relaçóes que se estabelecem entre o texto e o discurso dão uma dimensão sensível ao conteúdo, porque ele não é apenas veiculado pelo plano da expressão, mas recriado nele.

Segundo o autor, pode-se pensar o texto como rica possibilidade ao leitor iniciante de apreender e de materializar seus discursos e o dos outros no processo de apropriação da língua escrita. Acredita-se que somente dessa forma concretiza-se uma alfabetizaçáo que seja realmente significativa porque nela os discursos seriam valorizados.

Infelizmente, o que presenciamos hoje na maioria das salas de alfabetização brasileiras são trabalhos que reduzem a escrita à representação da oralidade. Essa redução do sistema gráfico à oralidade, conforme defende o método fônico, faz com que a escrita náo seja compreendida em sua complexidade, assim como ela realmente é constituída. Segundo Bajard (2006, p. 501)

Restrita às suas características grafofonéticas, o sistema gráfico acaba se reduzindo ao sistema alfabético. Réplica da oralidade, a língua escrita não seria suscetível de ser submetida a uma semiótica, reduzindo-se assim à sua funçáo de memória da oralidade. Não seria uma linguagem em si mesma; não teria capacidade de construir diretamente o pensamento. 
Foi em consonância com o autor, entendendo que o sistema gráfico não se limita apenas ao uso das letras, mas composto náo apenas por elas, mas pelo conjunto que elas compóem juntamente com o conjunto dos demais caracteres, que o presente trabalho valorizou, em vários momentos, os demais sinais gráficos, para além dos das letras, no contexto dos textos.

Após a atividade de marcação dos espaços em branco, realizou-se a atividade de projetar para os alunos o poema digitado em várias fontes de letras. Em seguida, a turma foi dividida em duplas e para cada uma delas foi oferecido o texto Leiláo de Jardim digitado em uma fonte diferente para que fizessem as marcaçôes dos espaços em branco entre as palavras. Nesse contexto, também foram feitas observaçóes pelas duplas, tais como: Vamos marcar todos os espaços! Agora é sua vez, já dei o enter! Este poema está cheio de espaços e de enters!

\section{Imagem 3 - Poema em diferentes fontes}

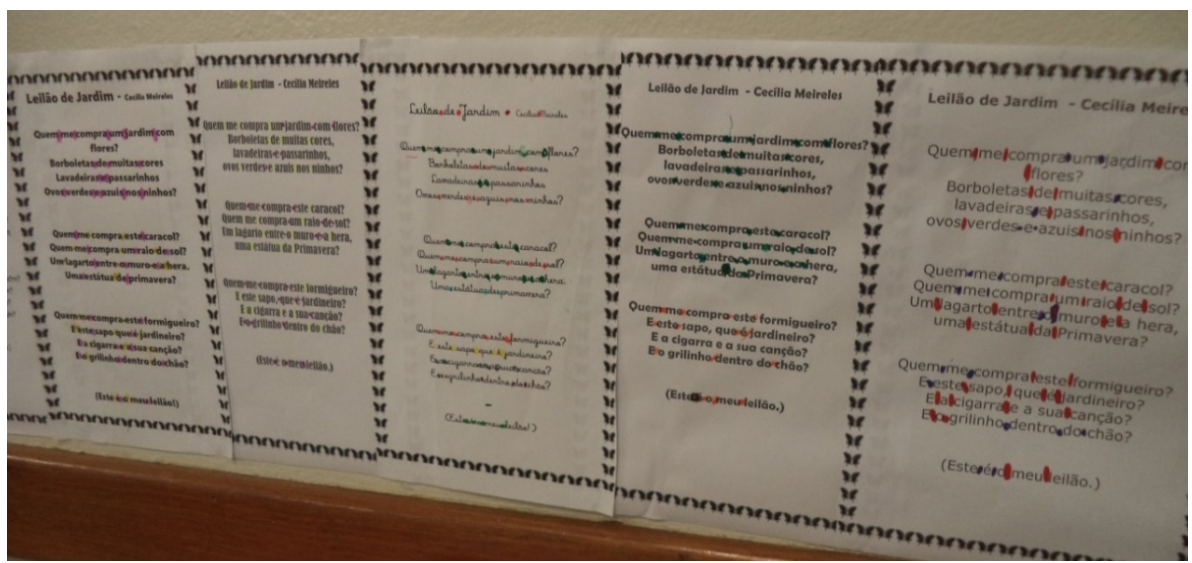

Fonte: Arquivo pessoal da pesquisadora.

A atividade de marcação dos espaços em branco, realizada pelas duplas, se concretizou como mais uma oportunidade de reconhecimento do texto em sua integralidade. Além de perceber o poema graficamente produzido em uma fonte diferente, as crianças puderam identificar as palavras por meio dos espaços.

Considera-se importante, ainda, afirmar que atividades como as duas apresentadas, de visualização do mesmo texto em diferentes fontes, tanto na projeção feita na lousa, em que a fonte do texto se transforma instantaneamente pelo comando do mouse do computador, e de fixaçáo dos textos impressos na parede também em diferentes fontes, colocam a criança diretamente com 
a situação real do mundo escrito, com a verdadeira forma em que os diversos textos se apresentam na sociedade. Smolka (2017, p. 37-38) ao discutir a Sociogênese e a História da aprendizagem da leitura e da escrita, levanta alguns questionamentos:

Como o mundo digital - o mundo na palma da mão, nas pontas dos dedos - afeta e constitui as relaçốes sociais? E como essas condiçóes impactam, afetam, constituem os modos de ensinar/aprender, os modos de alfabetizar nos dias de hoje? Como conceber a dimensão discursiva da alfabetizaçáo constituída no/pelo mundo digital? [...] É na contração ou na intensidade da memória/história que vou refletindo sobre como o trabalho de escritura, o ler e o escrever, se inscrevem no corpo e na atividade humana, (trans)formando-os; como aprender a ler e a escrever se inscreve no tempo, na história e na memória.

Tanto os questionamentos da autora como a sua expressão reflexiva sobre a apropriação da língua escrita ponderam sobre as diferentes formas de aprendizagem e de usos da linguagem que remetem também ao pensamento sobre seu ensino no contexto escolar. A autora, em diálogo com uma premissa de Platáo - "[...] É para poder esquecer que aprendemos a escrever..." (Platão, 1994 Apud SMOLKA, 2017, p. 38) -, discute como essa preocupaçáo se redimensiona e se apresenta contraditória na contemporaneidade:

Penso no conhecimento humano produzido e condensado em um dispositivo como um aparelho celular, que nos faz esquecer os modos e as condiçóes de sua produção; arquiva, para nos deixar esquecer, números, nomes, datas, informaçóes, e dispensa os modos de calcular e operar matematicamente; nos abre um mundo de contatos e nos dá acesso a um mundo de imagens e palavras; sintetiza, abrevia e simplifica modos de dizer. Pequeno artefato cultural, já totalmente integrado ao cotidiano de vida das pessoas e instituiçóes, que (trans)forma, profundamente, os (sentidos dos) modos de lembrar, os modos de ler e de escrever. (SMOLKA, 2017, p. 38).

Ao refletir sobre a asserção platônica característica e pertinente à nossa época e indagar sobre a produção da memória cultural, Smolka possibilita a 
retomada dos "[...] princípios da sociogênese do desenvolvimento humano e da primazia do interdiscurso - (que ancoram a alfabetização como processo discursivo), ressaltando a importância de teses cruciais formuladas por Vigotski."(SMOLKA, 2017, p. 39). Ao rememorar dois aspectos muito presentes na teoria vigotskiana que são a história e o princípio da significaçâo. Lembrando que esse último também é concebido na teoria bakhtiniana, a autora reafirma suas convicçóes apresentadas na década de 1980, considerando-as mais consistentemente sustentadas e ainda estimula o pensamento sobre as novas demandas à alfabetização. "É diante das condiçôes da contemporaneidade, isto é, buscando objetivá-las, que se torna relevante repensar os espaços de elaboração nas relaçôes de ensino e o gesto - histórico e cultural - de alfabetizar." (SMOLKA, 2017, p. 40, grifo da autora).

Com base nesses apontamentos da autora e no aspecto apresentado por meio da teoria de Vigotski acerca do entendimento de que a aprendizagem e a educação precedem o desenvolvimento humano e, ainda na concepção volochinoviana de que "[...] o signo se cria entre indivíduos, no meio social; é portanto indispensável que o objeto adquira uma significação interindividual" (VOLOCHÍNOV, 2014, p. 46), é que se entende como um desafio possível repensar o ensino dos atos culturais da leitura e da escrita em que a discursividade esteja em foco.

\section{Conclusão}

Por meio da valorização do discurso, compreendido como decorrência de sentido em que língua e ideologia se articulam, construído entre interlocutores, é possível pensar em diferentes modos de alfabetizar. Nas relaçóes interdiscursivas, no trabalho de transformaçáo das condiçóes em que os atos culturais de ler e escrever realmente transformem a atividade mental por meio da linguagem verbal, das açóes de pensar e falar mediadas pelos signos, enfim, por meio de um trabalho discursivo com o uso de textos foi possível materializar uma possibilidade metodológica que levasse em conta o uso da dupla caixa e a ampliar a noção de palavra no contexto da alfabetização.

As atividades desenvolvidas com esse texto e também com os outros, aqui não relatados, materializaram um trabalho com a língua constituído de sentidos ideologicamente singulares. Especificamente, durante as atividades realizadas com esse eixo, as crianças foram gradativamente percebendo a separaçáo que existe entre as palavras e as letras, por meio dos espaços, que permitem a leitura, diferentemente do texto sonoro, em que as palavras são ouvidas/pronunciadas numa única cadeia sonora. 
O desenvolvimento das atividades planejadas para este eixo evidenciou, no decorrer do processo, o que os estudos teóricos já haviam apontado sobre a importância de apresentar, desde o início do processo de alfabetização escolar, tanto as diferenciaçóes entre as letras maiúsculas e minúsculas como da explicitação do espaço em branco e sua função de separar as palavras, definindo-as. Esse trabalho realizado partindo da materialização gráfica do texto se apresentou profícuo tanto para a aprendizagem da língua escrita como para a apreensão das possibilidades discursivas apresentadas.

\section{Referências}

ARENA, Dagoberto Buim. A literatura infantil como produção cultural e como instrumento de iniciaçáo da criança no mundo da cultura. In: SOUZA, Renata Junqueira de. Ler e compreender: estratégias de leitura. São Paulo: Fapesp: Mercado de Letras, 2010. p. 13-44.

. Ensino e aprendizagem: perspectivas no campo da alfabetização. In: LONGHINI, Marcos Daniel. (Org.). O Uno e o diverso na educaçáo. Uberlândia: EDUFU, 2011. V.1, p.27-38.

BAJARD, Élie. Da escuta de textos à leitura. São Paulo: Cortez, 2007.

. Nova embalagem, mercadoria antiga. Educaçáo e Pesquisa, São Paulo, v. 32, set./dez. 2006. p. 493-507.

. A descoberta da língua escrita. São Paulo: Cortez, 2012.

Cortez, 1999.

Ler e dizer: compreensão e comunicação do texto escrito. São Paulo

BARROCO, Sônia M. S.; SUPERTI, Tatiane. Vigotski e o estudo da arte: contribuiçôes para o desenvolvimento humano. Psicologia \& Sociedade. 26 (1), 2014. p. 22-31. Disponível em: http://www.scielo.br/pdf/psoc/v26n1/04.pdf. Acesso em: 15 de ago. de 2018.

BERNARDIN, Jacques. As crianças e a cultura escrita. Porto Alegre: Artmed, 2003.

FIORIN, José L. Da necessidade da distinção entre texto e discurso. In: Brait Beth.; SILVA, Maria Cecília, S. (Orgs.). Texto ou discurso? São Paulo: Contexto, 2012. . Introduçáo ao pensamento de Bakhtin. São Paulo: Ática, 2006. 
GERALDI, J. W. O computador e o desenvolvimento de novas atividades: uma perspectiva epistemológica. In: GERALDI, J. W.; BENITES, M.; FICHTNER, B. Transgressóes convergentes: Vigotski, Bakhtin e Bateson. Campinas: Mercado de Letras, 2006.

JOLIBERT, Josette. Formando crianças leitoras. Porto Alegre: Artes Médicas, 1994.

JOLIBERT, Josette; JACOB, Jannette. Além dos muros da escola: a escrita como ponte entre os alunos e a comunidade. Porto alegre: Artmed, 2006.

MARCUSCHI, Luiz A. A oralidade no contexto dos usos linguísticos: caracterizando a fala. In: MARCUSCHI, Luiz A.; DIONISIO, A. P. Fala e escrita. Belo Horizonte: Autêntica, 2007.

POSSENTI, Sírio. Notas sobre língua, texto e discurso. In: Brait Beth.; SILVA, Maria Cecília, S. (Orgs.). Texto ou discurso? São Paulo: Contexto, 2012.

SMOLKA, Ana L. B. A criança na fase inicial da escrita: a alfabetização como processo discursivo. São Paulo: Cortez, 2012.

. Da alfabetização como processo discursivo: os espaços de elaboração nas relações de ensino. In: GOULART, Cecília M. A.; GONTIJO, Cláudia M. M.; FERREIRA, Norma S. A. (Orgs.). A alfabetizaçáo como processo discursivo: 30 anos de A criança na fase inicial da escrita. São Paulo: Cortez, 2017.

VIGOTSKI, L. S. Psicologia pedagógica. São Paulo: Martins Fontes, 2001.

A construçáo do pensamento e da linguagem. São Paulo: Martins Fontes, 2009.

VOLOCHÍNOV, Valentin. Marxismo e filosofia da linguagem: problemas fundamentais do método sociológico na ciência da linguagem. Trad. Michel Lahud e Yara F. Vieira. 16. ed. São Paulo: Hucitec, 2014.

Marxismo e filosofia da linguagem: problemas fundamentais do método sociológico na ciência da linguagem. Trad. Sheila Grillo e Ekaterina V. Américo. 1. ed. São Paulo: editora 34, 2017. 